\title{
Role of zinc-aspirin metal coordination complex in diabetic cataract induced in vitro in goat eye lens
}

\author{
Dimak Chand Sahu ${ }^{1, *}$, Girendra Kumar Gautam², Durga Prasad Panda ${ }^{3}$, Mohd. Akhtar Rasool ${ }^{4}$ \\ ${ }^{1,4}$ Research Scholar, ${ }^{2}$ Associate Professor and HOD, ${ }^{1,2,4}$ Faculty of Pharmacy, Bhagwant University, Ajmer, Rajasthan, ${ }^{3}$ Principal \\ cum Director, Dept. of Pharmacology, J.K. College of Pharmacy, Bilaspur, Chhattisgarh, India \\ *Corresponding Author: Dimak Chand Sahu \\ Email: dc.sahu0010@gmail.com
}

\begin{abstract}
Diabetes is one of the major health problems that affect a large number of human populations. Diabetic cataract is one of the most frequent ocular complications rising secondarily to the diabetes. Aspirin and its various coordination metal complex plays a significant role in reduction of diabetes as well as cataract. In this work it had been tried to find about role of the Zinc-Aspirin complex and its effect on diabetic cataract induced by fructose. The synthesized complex had been synthesized using Zinc chloride and Aspirin. The synthesized complex had shown to reduce the in vitro diabetic cataract induced by the fructose. It could be concluded that zinc-aspirin metal complex may significantly reduce the cataractogenesis caused by the diabetes in in vitro model of cataratogenesis.
\end{abstract}

Keywords: Diabetes, Cataract, in-vitro, Zinc Aspirin metal Complex.

\section{Introduction}

Cataract could be defined as specification of the lens. Cataract is one of the leading cause of visual impairment throughout the world, affecting the subjects not only physiologically also economically and socially. In India there are 12 million of cases of blindness out of which $81 \%$ of the subjects suffered from cataract. Diabetes is one of the most common but one of the dreadful diseases. In a study it was found that out of the whole world population 62 million subjects were currently diagnosed with diabetes and the number of subjects is going to increase from 171 million to 366 million in 2030. The risk factors for the development of cataract include Diabetes mellitus: drugs ultraviolet radiation smoking alcohol, nutrition, gender etc. Cataract secondary to diabetes is one of the most common complications that occurring secondary to diabetes. Aspirin and its metal complexes are used as anti-diabetic agent as well anticataract activity. The insulinomimetic properties of the following Zincaspirin metal complex had been the rationale behind using it as the metal ion in the coordination complex.

The prime controlling side effect of acidic NSAIDs is the gastrointestinal damage which occurs as a result of a dual insult, NSAID-mediated direct acidic damage caused by the free carboxyl group, followed almost concurrently by the deleterious systemic effect of inhibition of prostaglandin synthesis (Shoen and Vender, 1989). Loss of Gastrointestinal blood, in the case of aspirin, is mainly due to its local effect which has been confirmed by the absence of gastric bleeding after parenteral administration of aspirin in prominent doses that caused significant gastric damage when given by the oral route (Leonards and Levy, 1970).

Besides Zinc is known to possess antiulcer properties along with having anti-inflammatory activity. Zinc sulphate is given internally in doses of up to 220 $\mathrm{mg}$ (equivalent to $50 \mathrm{mg}$ of zinc) t.i.d. to assist wound healing. However, in high dosage it produces corrosive effects on gastric mucosa including ulceration which may be explained by its conversion to zinc sulphate in the stomach (Reynolds, 1989). Clinical studies have shown that oral administration of zinc sulphate at the same dose is quite beneficial in the treatment of human gastric ulcers. Laboratory animal investigations have also demonstrated the protective effect of zinc compounds against experimental ulcers, including gastric ulceration induced by electrical vagal stimulation (Cho and Ogle, 19771, methacholine (Cho et al., 19781, restraint stress (Cho and Ogle, 1978a1, pylorus occlusion (Ogle and Cho, 19771, ethanol (Wang et al., 1986) and acetic acid (Kong, 1990). Zinc reduces the inflammatory processes through different mechanisms which has been confirmed by the use of zinc sulphate in rheumatoid arthritis and in psoriatic arthritis at the dose already mentioned. Also reported that if zinc is complexes with an absorbable chelating agent, it will not only prevent emesis caused by zinc sulphate but will also enhance the gastrointestinal absorption of ionic zinc as zinc sulphate is otherwise poorly absorbed (Reynolds, 1989). Based on extensive literature survey the zinc chloride is better instead of zinc sulphate due to its high efficacy against ocular therapy under the producing anti cataractogenic properties. All these observations prompted us to synthesise and to evaluate the zinc complex of aspirin which may have the following advantages: (a) the free carboxyl group of aspirin will be masked; (b) the ulcero-genicity of aspirin may be further reduced by the direct gastro-protective action of zinc; (c) zinc may add to the anti-inflammatory effects of aspirin; (d) gastrointestinal absorption of aspirin as well as of zinc may be enhanced from the complexes form; and (e) zinc will be present in a better tolerated form. 


\section{Materials and Methods}

Aspirin of Indian pharmacopoeial grade, acetonitrile of spectrophotometric grade, while sodium bicarbonate, zinc Chloride and all other chemicals of analytical reagent grade were used. Carrageenan Lambda, type IV, was purchased from local vender of Bilaspur (C.G.) Mumbai glass and chemicals. Tripledistilled water was used in all studies.

Male albino rats (Porton strain) obtained from the Central Animal House, of Guru Ghasidas University (GGU), Bilaspur C.G. India were used for biological studies.

Preparation of Zinc Complex of Aspirin: Acetylsalicylic acid $(18.0 \mathrm{~g}, 0.1 \mathrm{~mol})$ was dissolved in a solution of sodium bicarbonate $(8.4 \mathrm{~g}, 0.1 \mathrm{~mol})$ in water $(120 \mathrm{ml})$. The solution was filtered and to it was added slowly and with constant stirring a solution of zinc sulphate heptahydrate $(14.4 \mathrm{~g}, 0.05 \mathrm{~mol})$ in water $(40$ $\mathrm{ml}$ ). Turbidity appeared which on keeping at $10-15^{\circ} \mathrm{C}$ led to the formation of white crystals. The crystals were filtered, washed with a minimum quantity of cold water, and dried under vacuum to constant weight to give the zinc complex of aspirin $(14.8 \mathrm{~g}, 64.6 \%)$; m.p. $116-118^{\circ} \mathrm{C}$.

Ph-Solubility Studies of Aspirin and Its Zinc Complex: Solubility measurements were carried out for both the compounds at $25^{\circ} \mathrm{C}$ in Britton and Robinson modified universal buffer solutions (combination of acetic acid/sodium acetate, phosphoric acid/sodium phosphate and boric acid/sodium borate, $0.05 \mathrm{M}$ each) adjusted to a constant ionic strength $(\sim 1$ of 0.175 with potassium chloride. Buffers were prepared at intervals of $1.0 \mathrm{pH}$ unit within the range of 1.75-8.75. The $\mathrm{pH}$ measurements were performed with a Control Dynamics $\mathrm{pH}$ meter. An excess of the drug was added to $10 \mathrm{ml}$ of each buffer and agitated vigorously for 3 $\min$ in an ultrasonicator. It was then filtered immediately in test tubes previously placed in a Block Thermostat (Grant, BT3, 20- $140^{\circ} \mathrm{C}$ ) maintained at $25^{\circ} \mathrm{C}$.

The equilibrium $\mathrm{pH}$ of the filtrate was recorded. Appropriate dilutions were carried out with $0.1 \mathrm{~N} \mathrm{HCl}$ and analysed at $275 \mathrm{~nm}$ using a standard plot of aspirin in the same media.

Induction of In-Vitro Cataract: Glucose at a concentration of $55 \mathrm{mM}$ was used to induce cataracts, when there is high concentrations of glucose in the lens, it metabolizes through the sorbitol pathway leading to accumulation of polyols (sugar alcohols) which causes over hydration leading to oxidative stress. A total of 18 lenses were used for the study. These lenses were incubated in artificial aqueous humor with concentration of glucose $5.5 \mathrm{mM}$ served as normal control and $55 \mathrm{mM}$ served as toxic control for 72 hours. Lens was divided into three groups each group containing 6 lenses: -

Group I: fructose $5.5 \mathrm{mM}$ (normal control).

Group II: fructose $55 \mathrm{mM}$ (toxic control).

Group III: fructose $55 \mathrm{mM}+$ Zinc-Aspirin metal complex in various doses.

Morphological and Photographic Evaluation: Goat lenses were placed on a graph paper with its surface posterior part touching the mesh. To measure lens opacity, pattern of graph number of squares clearly visible through the lens was observed.

\section{Result}

The Pale yellow colour Zinc-aspirin compound had been synthesized having melting point of $112-116^{\circ} \mathrm{C}$. (Fig. 1)

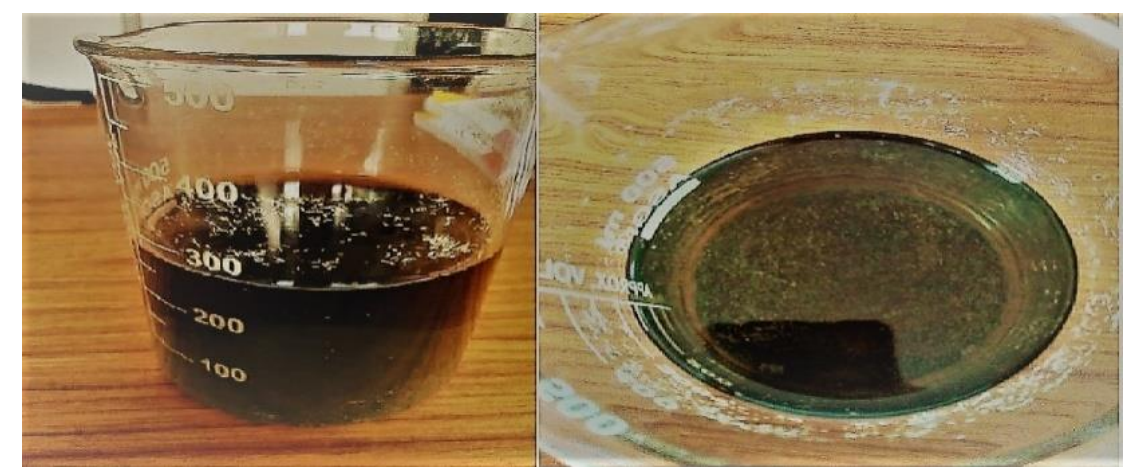

\section{Fig. 1: Zinc-aspirin metal complex}

All lenses in normal group remained transparent whilst all lenses in diabetic cataract opacities indicating cataract. The opacity gradually increased towards the centre with complete opacification by 72 hours indicating complete cataract genesis. Zinc-aspirin metal complex retarded the development of opacity compared to cataract group indicating the role of Zinc-aspirin metal complex in the management of cataract. (Fig. 2) 


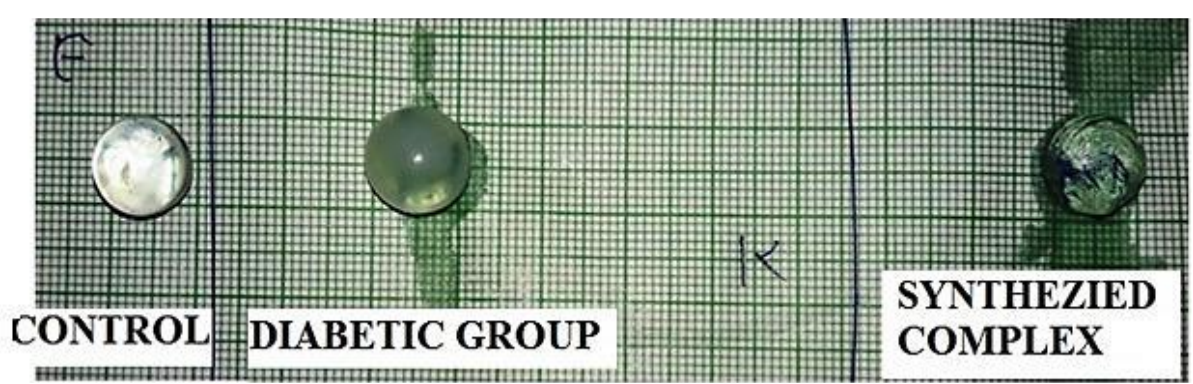

\section{Fig. 2: In vitro study on goat lens}

\section{Discussion}

Cataract is one of the most common complications of the diabetes. The current approach to manage the cataract is the surgical approach, but it was found out that significant number of surgical complications arises during these procedures; management by the pharmacotheruputical approach is the best suited alternative.

The cross-sectional study conducted by Bhattacharya et al. (2017) with the evidence that people in one of the developing state of India had average income less than 10000 rupees per month, the not very highly educated. The above evidence compels us draw conclusion that in a state where a large number of population had been not been educated, the awareness toward the health is very less and post-operative chances of complications arise due to lack of follow up visits after the surgery, an easy, patient compliance and economical system for diabetic cataract should be devised for maximum therapeutics effects with minimum obnoxious effects.

In this study, keeping the above mention points that had been concluded that synthesis of vanadiumaspirin coordination complex which was indented to show a significant reduction in the cataractogenesis induced secondary to diabetes induced by glucose in the goat lens. In vitro activity asserts the action against the diabetic cataract by reducing the lenticular opacity in the rat lens. In vitro experiment of Zinc-aspirin metal coordination complex helps us to conclude that Zincaspirin metal complex had an anti-cataract action.

\section{References}

1. Albert, A., Selective Toxicity, 4th Edn, Methuen, London, 1968, p. 328. Cho, C.H. and Ogle, C.W., A correlative study of the anti-ulcer effects of zinc sulphate in stressed rats. Eur J Pharmacol. 48(1978a)97-105.

2. Cho, C.H. and Ogle, C.W., Does increased gastric mucus play a role in the ulcer-protecting effects of zinc sulphate? Experientia. 34(1978b)90.

3. Cho, C.H. and Ogle, C.W., The effects of zinc sulphate on vagal-induced mast cell changes and ulcers in the rat stomach. Eur J Pharmacol. 1977;43:315-322.

4. Chvapil, M., New aspects in the biological role of zinc: a stabilizer of macromolecules and biological membranes. tife Sci. 1973;13;1041-1049.

5. Chvapil, M., Ryan, J.N. and Zukoski, CF., The effect of zinc and other metals on the stability of lysosomes. Proc Sac Exp Biol Med. 1972;140:642-646.
6. Joshi SR, Parikh RM. India - diabetes capital of the world: now heading towards hypertension. J Assoc Physicians India. 2007;55:323-4p.

7. James ER. The etiology of steroid cataract. J Ocul Pharmacol Ther. 2007;23(5):403-20p.

8. Kumar A, Goel MK, Jain RB, Khanna P, Chaudhary V. India towards diabetes control: Key issues. Australas Med J. 2013;6(10):524-31p.

9. Leske MC, Chylack LT, Wu SY. The lens opacities casecontrol study and Risk factors for cataract. Arch Ophthalmol. 1991;109:244-51p.

10. Van Heyningen R, Harding JJ. A case-control study of cataract in Oxfordshire: some risk factors. $\mathrm{Br} \mathrm{J}$ Ophthalmol. 1988;72(11):804-8p.

11. Wild S, Roglic G, Green A, Sicree R, King H. Global prevalence of diabetes-estimates for the year 2000 and projections for 2030. Diabetes Care. 2004;27(3):1047$53 \mathrm{p}$. 